\title{
Parental Influence on Social Anxiety in Children and Adolescents: Its Assessment and Management Using Psychodrama
}

\author{
Esther F. Akinsola, Pamela Arnold Udoka \\ Department of Psychology, Faculty of Social Sciences, University of Lagos, Lagos, Nigeria \\ Email: foluk6@yahoo.com,pamudoka@yahoo.com \\ Received December $18^{\text {th }}, 2012$; revised January $16^{\text {th }}, 2013$; accepted February $14^{\text {th }}, 2013$
}

\begin{abstract}
Available literature implicates hereditary disposition and environmental conditions in the development of social anxiety in children. Based on their early experiences children can perceive and interpret normal social situations and interactions negatively and as threatening. This perceptions can generate anxieties in them including social and performance anxieties. Based on this premise an attempt was made in this study to assess social and performance anxieties in some children and adolescents, determine the influence of parenting on the development of these anxieties and manage those with high levels of these anxieties using psychodrama as the therapeutic technique. 567 children and adolescents aged $7-16$ years, $(275$ males and 292 females) were assessed on social anxiety, performance anxiety, and parenting style scales. Participants who reported high levels of anxiety and who scored higher than the mean scores on the anxieties scales were managed using psychodrama. Results obtained indicated that permissive parenting style and its hybrids tend to promote the development of social and performance anxieties in the participants more than other parenting styles. In addition psychodrama as an intervention therapy was found to be effective in reducing the levels of social and performance anxieties in the participants managed.
\end{abstract}

Keywords: Parental Influence; Social Anxiety; Psychodrama

\section{Introduction}

\section{Parental Influence on Development}

Baumrind (1971) identified parental practices, which influence the developing child, as parenting style, and this parenting style was categorized into three types, namely authoritarian, authoritative, and permissive parenting styles. The permissive parenting style was later differentiated into neglectful and indulgent styles (Maccoby \& Martin, 1983).

According to Baumrind (1971), authoritarian parenting is restrictive and punitive, and places firm limits and controls on children with little or no verbal exchange. Authoritarian parenting is presumed to be associated with social incompetence and poor communication skills (Baumrind, 1991). Authoritative parents although put some limits and controls on their children's actions, but they allow extensive verbal dialogue which promotes parental responsiveness, and encourages independence, social and cognitive competence, self reliance and social responsibility in them. Authoritative parents make use of behavioural and monitoring controls to guide and direct their children's behaviour and provide them with reasons for their own actions. Authoritative parents encourage reciprocal communication with their children and are open to modifying their rules if and when necessary (Baumrind, 1967). In permissive parenting few or no rules and little or no controls are exerted over the children. Children under such parenting style are given complete freedom to make their life decisions and behave autonomously and independently (Baumrind, 1991). This type of parenting style was associated with social incompetence and lack of self control (Maccoby \& Martin, 1983, Baumrind, 1971).

In Nigeria, parental practices embrace all the parenting styles with emphasis on obedience and compliance with parental in- structions (Akinsola, 2011). Many Nigerian parents however accompany this demand for obedience and compliance with parental instructions with responsiveness, love, care, sensitivity, reciprocal dialogue, and explanations for their actions. The combination of demand for obedience and responsiveness by parents allows Nigerian children to perceive their parents as authoritative some of the time and authoritarian at other times.

Research evidence has indicated that authoritative and authoritarian parenting styles as well as their hybrids are significantly practiced by Nigerian parents (Akinsola, 2010a). It is therefore expected that children brought up under permissive and authoritarian parenting styles and their hybrids would report higher levels of social and performance anxieties than those brought up under authoritative parenting style.

\section{Social Anxiety}

Social anxiety involves exaggerated, persistent, irrational and disruptive fear of a particular object, a particular event, or a particular setting. Social anxiety becomes social anxiety disorder when it is very distressing or it interferes with work or school or other activities. Social anxiety disorder involves overwhelming anxiety and excessive self consciousness in everyday social situations (Bruce \& Saeed, 1999). People with social anxiety have a persistent, intense and chronic fear of being watched and judged by others and of being embarrassed by their own actions. Social anxiety disorder as defined in DSM-IV is characterized by a strong and persistent fear of social or performance situations in which the person concerned might feel embarrassment or humiliation (DSM-IV American Psychiatric association, 1994, 2000)

Available literature suggests that hereditary and environ- 
mental factors contribute to the development of social anxiety (Chandler,2012, Cuncic, 2012). This is because many children usually have one or even both parents with anxiety disorders. Besides behavioural inhibition which is the tendency to react negatively to new situations or people or things is believed to be inherited and can lead to social anxiety disorder (Chandler, 2012). Some children may be irritable as infants, shy and fearful as toddlers, cautious, quiet and introverted at the school age, and this trait may continue to show into adolescence and adulthood, and they appear more likely to develop social anxiety disorder (Schwartz, Snidman, \& Kagan, 1999). Children who consistently behave in this way are more likely to have parents who have anxiety disorders (Merikangas, Avenevoli, Dierker, \& Grillon, 1999). Children with social anxiety appear less interested in exploring new things, more likely to be embarrassed about what they say at school, how they look or be afraid of looking at or doing something stupid. Social phobia typically occurs between 11-19 years of age (Cuncic, 2012). Socially phobic children appear less likely to receive positive reactions from peers and anxious or inhibited children may isolate themselves (Spence, Donovan,\& Brechman-Toussaint, 1999; Rubin, \& Mills, 1988). It has also been found that parents of children with anxiety disorders tend to be isolated themselves, and that shyness in adoptive parents significantly correlated with shyness in adopted children (Bruch, 1989).

Environmental factors such as speech or language problems, disfiguring physical illness, abuse, neglect, and direct social experiences have also been linked with social anxiety. For instance, previous social experiences that are traumatic or humiliating have been found to be associated with the onset or worsening of social anxiety disorders especially those related to performance anxiety and fear of public speaking (Beidel, 1999, Beidel \& Turner, 1998). In addition parental practices are considered to be part of environmental factors that may affect the development of anxiety in children. In this regard, it has been suggested that children can acquire social anxiety or phobia through the processes of observational learning and parental psychosocial education. For example, direct experiences such as observing or hearing about the socially negative experiences of others or verbal warnings of social problems and dangers may make the development of social anxiety disorder more likely (Mineka, \& Zinbarg, 1995; Bidel, \& Turner, 1998). Societal attitude to shyness and avoidance has also been found to be related to social anxiety by affecting the ability to form relationships or access employment, or education and by causing shame (Okano, 1994). It has also been found that the effects of parenting are different depending on the culture. For instance in one study American children were found to be more likely to develop social anxiety disorder if their parents emphasize the importance of others' opinion and use shame as a disciplinary strategy, whereas in another study in China, it was found that shy and inhibited children were more accepted than their peers and more likely to be considered for leadership and considered competent (Xinyin, Rubin, \&Boshu, 1995). In countries such as Nigeria where children are to be seen and not heard and as such are trained to be timid and fearful of adults, parental input in the socialization of children or parental psychosocial education may generate social and performance anxieties in them.

\section{Social Anxiety \& Intervention Strategies}

Social anxiety has been found to be responsive to behav- ioural and cognitive behavioural therapy involving the use of exposure (gradual re-entry into feared situation), (Bruce \& Saeed, 1999). Components of cognitive behaviour therapy for social phobia have been found to include symptom management skills, social skill training, cognitive restructuring all of which are aimed at changing the patients' anxious thought processes and exposure. Studies that have examined components of behavioural and cognitive behavioural interventions for social anxiety reported that cognitive behaviour therapy involving exposure and focusing on changing phobic thinking can benefit as many as $75 \%$ of patients (Bruce \& Saeed, 1999).

Treadwell, Kumar, \& Wright (2005) combined the use of cognitive behavioural therapy with psychodrama to address the problems of college students and patients diagnosed with mood, substance abuse, anxiety and personality disorders. They found that the students and the clinical populations responded well to the cognitive behavioural techniques within the context of psychodrama. The techniques helped the clients to become aware of their habitual dysfunctional thought patterns and beliefs system that play an important role in mood regulation. The combination of the techniques provided a balance between an exploration of emotionally laden situations and a more concrete, data based, problem-solving process.

\section{Psychodrama}

Psychodrama is a therapeutic technique often used as a psychotherapy that uses group role playing and dramatic self presentation and spontaneous dramatization to investigate and gain insight into clients' lives. People in a psychodrama group act out scenes from one person's life to help them process the issue they want to address in therapy

Psychodrama was developed by Moreno (1889-1974), and includes elements of theatre which is often conducted on a stage where props can be used. By closely re-creating real-life situations and acting them out in the present, clients have the opportunity to evaluate their behaviour and more deeply understand a particular situation in their lives

A core tenet of psychodrama as postulated by Moreno is the theory of "spontaneity-creativity". Moreno believed that the best way for an individual to respond creatively to a situation is through spontaneity which is reflected by a readiness to improvise and respond in the moment. He believed that when people are encouraged to address a problem in a creative way by reacting spontaneously and on impulse they may begin to rediscover new solutions to the problems in their lives and learn new roles they can inhabit within it. The focus on spontaneous action within the psychodrama was developed in Moreno's "Theatre of Spontaneity". According to (Tomasulo, 2011), psychodrama is based on the premise that spontaneity and anxiety are inversely related such that the more spontaneous a person is the lower the person's anxiety. This in Tomasulo's view makes the use of psychodrama and role playing in therapy to be very effective in overcoming anxiety.

In a session of psychodrama, the therapist becomes the director and one member of the group becomes the protagonist and focuses on a particular situation to enact on stage. A variety of scenes may be enacted depicting memories of specific happenings in the clients' past. These scenes approximate real-life situations or external representation of inner mental processes within the individuals in the group. According to Coleman (2011), acting out scenes from a person's life allows other 
group members to address their past issues so that they can process them and move forward. He pointed out that without processing such past issues members of the role playing group cannot move ahead. Furthermore (Coleman, 2011), affirmed that psychodrama is effective for the treatment of disorders such as grief, loss, drug and alcohol addiction, depression and anxiety. Pramann (2005), also emphasized that psychodrama can be used to facilitate developmental repair, address the symptoms of post traumatic stress disorders and promote control, containment and stability.

\section{Psychodrama as Intervention Strategy}

Empirical research studies on the use of psychodrama as intervention therapy are scanty. Practitioners of psychodrama traditionally rely more on clinical experience than experimental research data. This is because research data on psychodrama are more descriptive than empirical

Some studies however have been carried out on classical psychodrama. Kellermann (1987) reviewed some studies that applied classical psychodrama. In one of such studies (Hall, 1977), compared the differences between an intensive weekend psychodrama experience, and six spaced (once a week) sessions. In the study 54 female nursing students were randomly assigned to the week-end group, spaced group, and control group. The two experimental groups had 18 hours experience each. The results indicated that the intense week-end group recorded significantly reduced feelings of anxiety, depression, and distress but such reduction was not recorded for spaced sessions' group, suggesting that long exposure to psychodrama may be unimportant. In another study (Shearon, 1975) studied the effectiveness of psychodrama on fourth grade students. He found that this approach was no more effective than reality therapy or bibliotherapy in improving the self esteem of the participants.

Petzold, (1979) in his own study found that most of his senior participants recorded improved social relations as a result of one year of psychodrama. In another study, Schramski, Feldman, Harvey, \& Holiman (1984), studied the effectiveness of psychodrama with adult correctional residents. They found that psychodrama was more effective than a non treatment control group in improving behaviour toward the environment. White, Rosenblatt, Love, \& little (1982) evaluated the effect of a community based project including psychodrama in the treatment of child abusing mothers. Results showed that psychodrama was effective in positively modifying the attitudes of the mothers through increasing their self-acceptance, self-Control, responsibility, and socialization. Carpenter \& Sandberg (1985) found that psychodrama was effective in improving ego strength and in developing socialization skills in a small group of delinquent adolescents. Newman and Hall (1971) also succeeded in treating socially dysfunctional college students with psychodrama. These research evidences lend support to the effectiveness of psychodrama in addressing the problems of adjustment, antisocial, anxiety and related disorders. On the strength of these reviews it was expected that the use of psychodrama would be effective in reducing social and performance anxieties in the participants studied. Hence the following hypotheses guided the study.

\section{Hypotheses}

1) Children brought up under authoritative parenting style and authoritative/authoritarian parenting style hybrid would be significantly represented in the sample studied.

2) The highest proportion of children who would report high levels of anxiety would be those brought up under the authoritarian/authoritative parenting style hybrid when compared to those brought up under other parenting styles.

3) Children brought up under the authoritarian/authoritative parenting style hybrid would report highest level of anxiety on all the anxiety measures when compared to those reported by children brought up under other parenting styles.

4) Psychodrama would be effective in reducing anxiety in the children such that post treatment scores in anxiety would be lower than pre-treatment scores.

\section{Method}

\section{Participants}

567 elementary school children aged between 7 and 16 years randomly selected from four different schools participated in the study. The participants were made up of 275 males and 292 females. It should be noted that the participants were not part of a clinical sample. They were not previously diagnosed as having anxiety disorder.

\section{Instruments}

Three assessment instruments were administered to the children. These were:

Children social anxiety scale;

Performance anxiety scale;

Parenting style scale.

\section{Children Social Anxiety Scale}

This scale consists of 20 items and was developed by the researchers taking into account the environmental context. The scale assesses levels of anxiety in the children. The scale has two parts. The first part evaluates the anxious events in the participants' lives, while the second part evaluates the frequency of the anxiety provoking events and which was measured by frequency of avoidance. Examples of items in the scale are: "Telephoning in public gives me (no anxiety, mild anxiety, severe anxiety); I avoid it - (all the time, once a while, never); Acting, performing or talking in front of people I don't know gives me- (no anxiety, mild anxiety, severe anxiety); I avoid it -(all the time, once a while, never). The response to the first part of the scale varied on a 3-point scale where severe anxiety is scored 3 and no anxiety 1 . For the second part, all the time is scored 3 and never is scored 1 . The split half reliability coefficients for the two parts of the anxiety scale were found to be $0.39, p<.01$, and $0.59, p<.01$, respectively. Norms were established for the two parts of the scale as well.

\section{Performance Anxiety Scale}

This scale was also developed by the researchers. The scale consists of 20 items designed to assess the way children feel when they meet, greet, talk or perform in front of their friends, strangers, or a large group of people. Examples of items in the scale are: describe how you feel anytime you know you are going to meet, greet, talk or perform in front of your friends, strangers or a large number of people. Responses to such items 
include (my mouth becomes dry, I start sweating in my palms). Responses to the scale varied on a 3-point scale of (all the time, some of the time, none of the time). The split half reliability coefficient for the scale was found to be $0.58, p<.01$. Norms were also established for this scale.

\section{Parenting Style Scale}

The parenting style scale was adapted from (Baumrind's 1971) parental care scale. It consists of 20 items designed to assess the parenting styles under which the children were brought up.

5 of the items measures permissive style, 6 items measures authoritarian style and 9 items measures authoritative style. Examples of items in the scale include: my parents respect my privacy, "My parents give me a lot of freedom". Responses to the scale items varied on a 3-point rating of (agree, uncertain, disagree). For permissive style the number of items is five. If a child is uncertain for all the items, the score would be 10 . Therefore any score that is higher than 10 is taken as permissive score, any score higher than 12 is taken as authoritarian score and any score higher than 18 is taken as authoritative score. The split half reliability coefficient for the scale was found to be $0.39, p<.01$; five weeks interval test retest reliability for the three styles were found to be Permissive- 0.67 , authoritarian-0.35, Authoritative $-0.80, p<.01$.

\section{Procedure}

For the assessment stage the three instruments were administered to the children after ensuring that they understood the instructions and what they were expected to do. For the management phase, and based on the average mean scores of all the participants, some of the children who scored higher than the average mean scores were selected as the management sample. This sample consisted of 50 children and their scores were rank ordered from highest to lowest. Out of this sample 24 of them that had the highest anxiety scores participated in the management phase.

\section{Management}

Psychodrama was used as the therapeutic technique. This method of therapy consists of three stages. The stages are: the warm up stage, the action stage and the sharing stage.

At the warm up stage the director (one of the researchers) interacted with the children and encouraged them to talk about those situations that make them shy or afraid and they were asked to choose partners and get acquainted with them.

The action stage started with selection of the antagonist (one of the participants). The antagonist was told to act out or reenact some of the anxiety provoking situations that were discussed at the warm up stage. Scenes involving head-teacherstudent, mother/father/children, and eating in public places were re-enacted. There after a protagonist was chosen amongst those who had the fear of public speaking to act as the VC of the University and to address the staff school children. All the activities enacted involved all the items in the performance inventory scale and the children Social anxiety scale. These activities were aimed at showing the children that their perceived anxiety was nothing other than a distortion of the mind.

In the sharing stage the group members were invited to ex- press and share their feelings on what they now understand as anxiety. After this interactive session the post test was given to the children to find out if any significant changes had occur red as a result of the therapeutic sessions. The psychodrama therapy was carried out in three days.

\section{Results}

\section{Frequency Distribution Statistics}

\section{Hypothesis One}

Children brought up under authoritative parenting style and authoritative/authoritarian parenting style hybrid would be significantly represented in the sample studied.

From Table 1 above out of 565 participants 273 or $48.3 \%$ of the children reported being brought up under the authoritative/authoritarian parenting style hybrid. The chi-square $\left(\mathrm{x}^{2}\right)$ value for this proportion is 8.54 and it is significant at $p<.01$. Similarly out of 565 children studied 79 of them or $14 \%$ reported being brought up under authoritative parenting style. The chi-square $\left(\mathrm{x}^{2}\right)$ value for this proportion is 3.92 and it is also significant at $p<.01$. In addition out of the 565 children who participated in this study, 113 or $20 \%$ of them reported being brought up under the permissive/authoritative/authoritarian parenting style hybrid. Furthermore the chi-square $\left(\mathrm{x}^{2}\right)$ value for this proportion is 4.75 and it is significant at $p<.01$. By these results the first hypothesis is thus supported and an additional hybrid the permissive/authoritarian/authoritative parenting style hybrid is also significantly represented.

\section{Hypothesis Two}

The highest proportion of children who would report high levels of anxiety would be those brought up under the authoritarian/authoritative parenting style hybrid when compared to those brought up under other parenting styles.

A look at Table 2, showed that the highest number of children that reported high levels of social anxiety, highest frequency of anxiety and highest levels of performance anxiety were those brought up under the authoritative/authoritarian parenting style hybrid with proportions of $(142 / 295,48.14 \%)$, $(145 / 276,52.54 \%)$, and $(109 / 266,40.98 \%)$. The chi-squares $\left(\mathrm{x}^{2}\right)$ for these proportions are: $8.51,9.11$, and 7.62 respectively.

Table 1.

Distribution of parenting styles and their hybrids in the sample.

\begin{tabular}{cccc}
\hline Parenting style & No & $\%$ & $\mathrm{x}^{2}$ \\
\hline Permissive & 11 & 1.9 & \\
Authoritarian & 13 & 2.3 & \\
Authoritative & $\mathbf{7 9}$ & $\mathbf{1 4}$ & $\mathbf{3 . 9 2}^{*}$ \\
Permissive \& authoritarian & 19 & 3.4 & \\
Permissive \& authoritative & $\mathbf{3 7}$ & 6.5 & \\
Authoritarian \& authoritative & $\mathbf{2 7 3}$ & $\mathbf{4 8 . 3}$ & $\mathbf{8 . 5 4}^{*}$ \\
Perm/authoritarian/authoritative & $\mathbf{1 1 3}$ & $\mathbf{2 0 . 0}$ & $\mathbf{4 . 7 5}$ \\
Undifferentiated & 20 & 3.5 & \\
Total & 565 & 100 & \\
\hline
\end{tabular}

Note: Chi-square table values are: $\left.\left(\mathrm{x}^{2}=1.96, p \leq .05 ; 2.58, p \leq .01\right)\right)$ 
Table 2.

Distribution of high levels of anxiety according to parenting styles.

\begin{tabular}{|c|c|c|c|c|c|c|}
\hline Parenting Style & Social Anxiety No & $\%$ and $x^{2}$ & Anxiety Frequency No & $\%$ and $x^{2}$ & Performance Anxiety No & $\%$ and $x^{2}$ \\
\hline Permissive & 7 & 2.37 & 2 & 0.73 & 7 & 2.63 \\
\hline Authoritarian & 6 & 2.03 & 7 & 2.54 & 4 & 1.50 \\
\hline Authoritative & 40 & $\begin{array}{l}13.56 \\
3.41^{* *}\end{array}$ & 32 & $\begin{array}{l}11.59 \\
2.98 * *\end{array}$ & 39 & $\begin{array}{l}14.66 \\
3.98\end{array}$ \\
\hline Permissive/Authoritarian & 9 & 3.05 & 8 & 2.90 & 14 & 5.26 \\
\hline Permissive/Authoritative & 22 & 7.46 & 13 & 4.71 & 25 & $\begin{array}{c}9.40 \\
3.79^{* *}\end{array}$ \\
\hline Authoritarian/Authoritative & 142 & $\begin{array}{l}48.14 \\
8.51^{* *}\end{array}$ & 145 & $\begin{array}{l}52.54 \\
9.11^{* *}\end{array}$ & 109 & $\begin{array}{l}40.98 \\
7.62^{* *}\end{array}$ \\
\hline Perm/Authoritarian/Authoritative & 61 & $\begin{array}{l}20.68 \\
4.82^{* *}\end{array}$ & 59 & $\begin{array}{l}21.38 \\
4.98^{* *}\end{array}$ & 63 & $\begin{array}{l}23.68 \\
5.11^{* *}\end{array}$ \\
\hline Undifferentiated & 8 & 2.71 & 10 & 3.62 & 5 & 1.88 \\
\hline Total & 295 & 100 & 276 & 100 & 266 & 100 \\
\hline
\end{tabular}

Note: Chi-square $\left(\mathrm{x}^{2}\right)$ table values are: $\mathrm{x}^{2}=1.96, p \leq .05,2.58, p \leq .01$.

The values are significant at $p<.01$. The next high frequency of children that reported high levels of social anxiety, frequency of anxiety and high levels of performance anxiety were children brought up under the permissive/authoritarian/authoritative parenting style hybrid. The proportions are: $(61 / 295,20.68 \%)$, $(59 / 276,21.38 \%)$, and $(63 / 266,23.68 \%)$. The chi-square values for these proportions are: 4.82, 4.98, and 5.11 respectively. These values are significant at $p<.01$. The next high frequency involved those children brought up under the authoritative parenting style. The proportions of these children that reported high levels of anxiety are: $(40 / 295,13.56 \%),(32 / 276,11.59 \%)$ and $(39 / 266,14.66 \%)$. The chi-square values for the proportions are: $3.41,2.98$, and 3.98 respectively. Similarly they are significant at $p<.01$. The last significant frequency of children that reported high levels of performance anxiety were those brought up under the permissive/authoritative parenting style hybrid. The proportion is: $(25 / 266,9.40 \%)$. The chi-square value for this proportion is 2.61 , and the value is significant at $p$ $<.01$. These results support the second hypothesis.

\section{Descriptive Statistics Results}

The scores in Table 3 represent the norms for the social and performance anxiety scales. The participants that participated in the management phase were selected from those who scored higher than the mean scores reported above. The mean scores and standard deviations of anxiety measures according to the three single parenting styles are reported in Table 4.

From Table 4 above it is observed that children brought up under permissive parenting scored highest in social anxiety and performance anxiety. For frequency of anxiety, children brought up under the authoritarian parenting style had the highest score. However these differences were not statistically significant.

\section{Hypothesis Three}

Children brought up under the authoritarian/authoritative parenting style hybrid would report the highest level of anxiety on all the anxiety measures when compared to those reported
Table 3.

Means and standard deviation scores of the participants in the measures.

\begin{tabular}{cccc}
\hline & No & Mean & Standard Dev. \\
\hline Social anxiety & 565 & 37.56 & 6.84 \\
Frequency of anxiety & 565 & 40.00 & 7.35 \\
Performance anxiety & 565 & 35.02 & 5.91 \\
\hline
\end{tabular}

Table 4.

Means \& Std. deviation of anxiety scores according to the three main parenting styles.

\begin{tabular}{ccccccc}
\hline $\begin{array}{c}\text { Parenting } \\
\text { style }\end{array}$ & \multicolumn{2}{c}{$\begin{array}{c}\text { Social } \\
\text { anxiety }\end{array}$} & \multicolumn{2}{c}{$\begin{array}{c}\text { Frequency } \\
\text { of anxiety }\end{array}$} & \multicolumn{2}{c}{$\begin{array}{c}\text { Performance } \\
\text { anxiety }\end{array}$} \\
\hline Mean & Std Dev. & Mean & Std. Dev. & Mean & Std. Dev. \\
$\begin{array}{c}\text { Permissive } \\
\text { No }=11\end{array}$ & 38.64 & 5.99 & 37.00 & 6.51 & 37.55 & 4.50 \\
$\begin{array}{c}\text { Authoritarian } \\
\text { No }=13\end{array}$ & 36.38 & 5.42 & 42.46 & 9.73 & 33.23 & 6.06 \\
$\begin{array}{c}\text { Authoritative } \\
\text { No }=79\end{array}$ & 36.15 & 7.93 & 39.40 & 6.58 & 34.63 & 6.41 \\
\hline
\end{tabular}

by children brought up under other parenting styles.

From Table 5 above children brought up under permissive/authoritarian hybrid scored highest in performance anxiety followed by those under permissive/authoritative hybrid, followed by those under permissive/authoritative/authoritarian hybrid then authoritarian/authoritative hybrid and lastly those under the undifferentiated hybrid in that order. Children brought up under the permissive/authoritative hybrid scored highest in social anxiety. This is followed by those brought up under permissive/authoritative/authoritarian hybrid. Children brought up under the undifferentiated hybrid scored lowest in social anxiety. For frequency of social anxiety children brought up under permissive/authoritarian/authoritative hybrid had the highest score, while those brought up under permissive/authoritarian hybrid had the least score. In other to determine if these differ- 
ences are significant the data was subjected to analysis of variance test. The results are presented in Table 6.

From Table 6 below, the difference in mean scores is significant only for performance anxiety. As can be seen in Table 5 below those children brought up under permissive/authoritarian hybrid scored highest on performance anxiety, and those brought up under undifferentiated hybrid scored lowest. These results do not support hypothesis three. On the contrary the results suggest that permissive parenting style and its hybrids tend to promote anxiety more in children than other parenting styles.

\section{Hypothesis Four}

Psychodrama will be effective in reducing anxiety in the children such that post treatment scores in anxiety would be lower than pre-treatment scores.

From Table 7 it is evident that psychodrama was effective in reducing social and performance anxiety in the children. The pre-test and post-test mean scores of the children are: (Social anxiety: 29.08, 21.75, $\mathrm{t}=8.12, p<.01$ ); (Frequency of anxiety: $37.87,30.43, \mathrm{t}=2.68, p<.05$ ); and (Performance anxiety: $31.79,27.92, \mathrm{t}=2.36, p<.05)$. These pre and post test mean scores are significantly different. Therefore by these results the fourth hypothesis is supported.

\section{Discussion}

Major Findings:

1) Children brought up under authoritative parenting style, authoritarian/authoritative parenting style, permissive/authoritarian/authoritative parenting style and permissive/authoritative parenting style were significantly represented in the sample studied.

2) The highest proportion of children who reported higher levels of anxiety (higher than the norm), was for children brought up under authoritarian/authoritative parenting style hybrid.

3) Children brought up under permissive/authoritarian parenting hybrid reported the highest level of performance anxiety.

4) Psychodrama was found to be effective in reducing anxiety levels in the children.

In terms of frequency distribution, children brought up under authoritarian/authoritative parenting style were highest in number in the total sample and highest in number that reported the three levels of anxiety studied. This is followed by the

Table 5.

Mean scores \& Std. Deviation of anxiety scores according to parenting style hybrids.

\begin{tabular}{ccccccc}
\hline & \multicolumn{2}{c}{ Social Anxiety } & \multicolumn{2}{c}{ Frequency of anxiety } & \multicolumn{2}{c}{ Performance anxiety } \\
\hline & Mean & Std. Dev. & Mean & Std. Dev. & Mean & Std. Dev. \\
Perm/authoritarian No $=19$ & 36.74 & 10.85 & 37.58 & 10.61 & 38.26 & 5.48 \\
Permissive/authoritative No $=37$ & 38.78 & 7.11 & 38.97 & 4.95 & 37.24 & 4.61 \\
Authoritarian/authoritative No $=273$ & 37.77 & 6.40 & 40.22 & 6.89 & 34.08 & 5.88 \\
Perm/authoritative/authoritarian. No $=113$ & 38.15 & 6.05 & 40.81 & 7.74 & 36.72 & 5.31 \\
Undifferentiated No $=20$ & 35.45 & 7.88 & 39.10 & 11.62 & 32.40 & 6.31 \\
\hline
\end{tabular}

Table 6.

ANOVA summary table for all the anxiety variables.

\begin{tabular}{cccccc}
\hline Measures & Source & SSQ & df & MSQ & F \\
\hline \multirow{2}{*}{ Social anxiety } & Between & 181.81 & 4 & 45.45 & \\
& Within & 20347.27 & 457 & 44.52 & 1.02 \\
& Total & 20529.08 & 461 & & \\
& Between & 249.05 & 4 & 62.263 & \\
Frequency of social anxiety & Within & 25088.75 & 457 & 54.90 & \\
& Total & 25337.80 & 461 & & \\
& Between & 1088.02 & 4 & 272.01 & $8.05^{*}$ \\
Performance anxiety & Within & 14632.02 & 457 & 32.02 & $p<.05$ \\
& Total & 15720.04 & 461 & & \\
\hline
\end{tabular}

Table 7.

Pre \& post test scores of children in the anxiety measures.

\begin{tabular}{cccccc}
\hline & \multicolumn{2}{c}{ Pre-test $(\mathrm{N}=24)$} & \multicolumn{2}{c}{ Post-test $(\mathrm{N}=24)$} & $\mathrm{t}$ \\
\hline Mean & Std. Dev. & Mean & Std. Dev. \\
Social anxiety & 29.08 & 3.50 & 21.75 & 2.71 & $8.12^{* *}$ \\
Frequency of anxiety & 37.87 & 7.53 & 30.43 & 11.22 & $2.68^{*}$ \\
Performance anxiety & 31.79 & 6.37 & 27.92 & 4.91 & $2.36^{*}$ \\
\hline
\end{tabular}

Note: ${ }^{* *} p<.01 ;{ }^{*} p<.05$ 
number of those brought up under the combination of the three parenting styles namely the permissive/authoritarian/authoritative parenting style hybrid. Next in number is the children brought up by authoritative parents. The significant representation of the children brought up under the authoritarian/authoritative parenting style in this study agrees with earlier findings (Akinsola, 2010, 2011) that this parenting style hybrid is significantly and commonly practiced in Nigeria. One important observation is the fact that in the earlier studies (Akinsola, 2010, 2011) in which young people served as the participants authoritative parenting recorded the highest frequency of participants followed by the authoritarian/authoritative parenting. However in this study, where children served as participants, the authoritarian/authoritative parenting hybrid recorded the highest frequency of participants. The implication here seems to be that as Nigerian children grow up and mature, they tend to perceive their parents more as authoritative and less as authoritarian.

The findings of this study as depicted in (Table 3) suggest that permissive parenting tend to promote the highest level of social and performance anxiety in the children when compared to the levels of anxiety being promoted by other parenting styles and the levels of anxiety reported by the total sample (Table 3). Though this tendency was not statistically significant, it was significant that children brought up under the permissive/authoritarian parenting style reported the highest level of performance anxiety. These findings reflect the contribution of parental psychosocial education embedded in parenting styles to the development of social anxiety in Nigerian children, and the fact that all types of parenting style promote anxiety in children raised under them, with authoritative parenting promoting the least anxiety and permissive parenting promoting the highest level of anxiety in the children. The influence of parenting styles on social anxiety in children demonstrated in this study also reflect societal attitude to shyness and cultural dimension of parental socialisation of Nigerian children. The traditional Nigerian society believes that children are to be seen and not heard and as such child training method promotes timidity and shyness in the children.

Psychodrama was found to be effective in reducing anxieties in the children who went through therapy. This finding agrees with the findings of Hall (1977), White et al. (1982), and Carpenter, \& Sandberg) (1985). Hall, (1997) found the intensive weekend psychodrama experience effective in significantly reducing feelings of anxiety, depression and distress in nurses, while White et al. 1982, found psychodrama effective in modifying child abusing mothers' attitude and in improving their self control and socialisation. Carpenter, \& Sandberg, 1985, in their own research, found psychotherapy effective in improving ego strength and in developing social skills in delinquent adolescents. The present finding further confirms the effectiveness of psychodrama in reducing social and performance anxieties and promoting public appearance confidence. Of note is the fact that the children who went through psychodrama therapy were not clinical samples. However given the success of the therapy it can be confidently inferred that psychodrama therapy can be effective in reducing anxieties in Nigerian clinical samples. In addition some cognitive restructuring of the children's feelings about the objects or situations provoking fears or anxieties in them was carried out. It is therefore suggested that it is needful to combine psychodrama therapeutic approach with cognitive restructuring to ensure effective and enduring outcome of psy- chodrama therapy.

\section{REFERENCES}

Akinsola, E. F. (2011). Relationships between parenting style, family type, personality disposition and academic achievement of young people in Nigeria. Ife PsychologIA, 19, 246-267.

Akinsola, E. F. (2010a). Correlation between parenting styles and sexual attitudes of young people in Nigeria: comparison of two ethnic groups. Gender and Behaviour, 8, 2771-2788.

American Psychiatric Association (1994). Diagnostic and statistical manual of mental disorders (4th ed.). Washington DC: American Psychiatric Association.

American Psychiatric Association (2000). Anxiety disorders. In Diagnostic and statistical manual of mental disorders (pp. 450-456). Washington DC: American Psychiatric Association.

Baumrind, D. (1967). Child care practices anteceding three patterns of preschool behaviour. Genetic Psychology Monograph, 75, 43-88.

Baumrind, D. (1971). Current patterns of parental authority. Developmental Psychology Monograph, 4, 1-103. doi:10.1037/h0030372

Baumrind, D. (1991). The influence of parenting style on adolescent competence and substance use. Journal of Early Adolescence, 11, 56-95. doi:10.1177/0272431691111004

Beidel, D. C. (1999). Psychopathology of childhood social phobia. Journal of the American Academy of Child and Adolescent Psychiatry, 38, 643-650. doi:10.1097/00004583-199906000-00010

Beidel, D. C., \& Turner, S. M. (1998). Shy children, phobic adults: The nature and treatment of social phobia. American Psychological Association Books.

Bruce, T. J., \& Saeed, S. Y. A. (1999). Social anxiety disorder: A common under-recognised mental disorder. American Family Physician, 60, 2311-2320

Bruch, M. A. (1989). Familial and developmental antecedents of social phobia: Issues and Findings. Clinical Psychology Review, 9, 37-47. doi:10.1016/0272-7358(89)90045-7

Carpenter, P., \& Sandberg, S. (1985). Further psychodrama with delinquent adolescents. Adolescence, 20, 599-604.

Chandler, J. (2012). Social anxiety disorder in children and adolescents. URL (last checked 17 September 2012).

http://www.dis.com/chandler/pamphlet/socphob/socphobpamphlet.ht $\mathrm{m}$

Coleman, B. (2011). Psychodrama produces dramatic results in therapy. URL (last checked 17 September 2012). http://4therapy.com

Cuncic, A. (2012). Modeling social skills to your child with social anxiety disorder. URL (last checked 17 September 2012). $\mathrm{http}: / /$ socialanxietydisoder.about.com/od/childrenandsad/a/rolemodel .hmt

Hall, I. (1977). The effects of an intensive weekend psychodrama versus spaced psychodrama sessions on anxiety, distress and attitude toward group interaction in nursing students. Ph.D. Dissertation, Mexico: University of Mexico.

Kellermann, P. F. (1987). Outcome research in classical psychodrama. Group Behaviour, 18, 459-469. doi:10.1177/104649648701800402

Maccoby, E. E., \& Martin, J. A.(1983). Socialization in the context of the family: Parent-child interaction. In P. H. Mussen, (Ed.), Handbook of child psychology (4th edition). New York: Wiley.

Merikangas, A. S., \& Grillon, D. L. (1999). Vulnerability factors among children at risk for anxiety disorders. Biological Psychiatry, 46, 15231535. URL (last checked 17 September 2012). http://www.en.wikipedia.org/wiki/Social_anxiety_disorder

Mineka, S., \& Zinbarg, R. (1995). Conditioning and ethological models of social phobia. In R. Heimberg, M. Liebowitz, D. Hope, \& F. Schneier, (Eds.), Social phobia: Diagnosis, assessment and treatment (pp. 134-162). New York: Guilford Press.

Moreno, J. L. (1953). Who shall survive? Foundations of sociometry, group psychotherapy and psychodrama. Beacon, NY: Beacon House.

Newman, G, \& Hall, R. C. W. (1971). Acting out: An indication for psychodrama. Group Psychotherapy, Psychodrama, \& Sociometry, 24, 87-96

Okano, K. (1994). Shame and social phobia: A transcultural viewpoint. 


\section{E. F. AKINSOLA, P. A. UDOKA}

Bull Menninger Clinical, 58, 323-338. URL (last checked 17 September 2012).

http://www.en.wikipedia.org/wiki/Social_anxiety_disorder

Petzold, H. (1979). Psychodrama therapie: Theorie, methoden, anwendung in der arbeit mit alten Menschen. Paderborn: Junfermann.

Pramann, R. (2005). Enhancing treatment effectiveness: Using psychodrama to address the trauma and pain of victims and perpetrators. Paper Presented at the Utah Domestic Violence Council's 11th Annual Domestic Violence Treatment Conference.

Rubin, K. H., \& Mills, R. S. (1988). The many faces of social isolation in childhood. Journal of Consulting and Clinical Psychology, 56, 916-924. URL (last checked 17 September 2012).

http://content.apa.org/journals/ccp/56/6/916

Schramski, T. G., Feldman, C. A., Harvey, D. R., \& Holiman, M. A. (1984). A comparative evaluation of group treatment in an adult correctional facility. Journal of Group Psychotherapy, Psychodrama and Sociometry, 36, 133-147.

Schwartz, C., Snidman, N., \& Kagan, J., (1999). Adolescent social anxiety as an outcome of inhibited temperament in childhood. Journal of American Academy of Child and Adolescent Psychiatry, 38, 1008-1015. URL (last checked 17 September 2012).

http://www.en.wikipedia.org/wiki/Social_anxiety_disorder

Shearon, E. M. (1975). The effect of psychodrama treatment on pro- fessed and inferred self concepts of selected fourth graders in one elementary school. Ph.D Dissertation, Gainesville, FL: University of Florida.

Spence, S. H., Donovan, C., \& Brechman-Toussaint, M. (1999). Social skills, social outcomes, and cognitive features of childhood social phobia. Journal of Abnormal Psychology, 108, 211-221. URL (last checked 17 September 2012).

http://content.apa.org/journals/abn/108/2/211

Tomasulo, D. J. (2011). Psychodrama, spontaneity \& anxiety: The more spontaneous you are the lower your anxiety. The Healing Crowd: Psychology Today, 4 February 2011.

Treadwell, T., Kumar, V. K., \& Wright, J. H. (2005). Enriching psychodrama through the use of cognitive behavioural therapy techniques. Unpublished manuscript. URL (last checked 17 September 2012). http://Psychodrama and Cognitive therapy.pdf

White, E. W., Rosenblatt, E., Love, A., \& Little, D. (1982). Psychodrama and life skills: A treatment alternative in child abuse. Unpublished Manuscript, Toronto: Center for Psychodrama and Sociometry.

Chen, X. Y., Rubin, K. H., \& Boshu, L. (1995). Social and school adjustment of shy and aggressive children in China. Development and Psychopathology, 7, 337-349. doi:10.1017/S0954579400006544 